\title{
Informatics for practicing anatomical pathologists: marking a new era in pathology practice
}

\author{
Manal Y Gabril ${ }^{1}$ and George M Yousef Y,3 $^{2,3}$ \\ ${ }^{1}$ Department of Pathology, London Health Sciences Centre, London, Canada; ${ }^{2}$ Department of Laboratory \\ Medicine, and the Keenan Research Centre in the Li Ka Shing Knowledge Institute St Michael's Hospital, \\ Toronto, Canada and ${ }^{3}$ Department of Laboratory Medicine and Pathobiology, University of Toronto,
}

Toronto, Canada

\begin{abstract}
Informatics can be defined as using highly advanced technologies to improve patient diagnosis or management. Pathology informatics had evolved as a response to the overwhelming amount of information that was available, in an attempt to better use and maintain them. The most commonly used tools of informatics can be classified into digital imaging, telepathology, as well as Internet and electronic data mining. Digital imaging is the storage of anatomical pathology information, either gross pictures or microscopic slides, in an electronic format. These images can be used for education, archival, diagnosis, and consultation. Virtual microscopy is the more advanced form of digital imaging with enhanced efficiency and accessibility. Telepathology is now increasingly becoming a useful tool in anatomical pathology practice. Different types of telepathology communications are available for both diagnostic and consultation services. The spectrum of applications of informatics in the field of anatomical pathology is broad and encompasses medical education, clinical services, and pathology research. Informatics is now settling on solid ground as an important tool for pathology teaching, with digital teaching becoming the standard tool in many institutions. After a slow start, we now witness the transition of informatics from the research bench to bedside. As we are moving into a new era of extensive pathology informatics utilization, several challenges have to be addressed, including the cost of the new technology, legal issues, and resistance of pathologists. It is clear from the current evidence that pathology informatics will continue to grow and have a major role in the future of our specialty. However, it is also clear that it is not going to fully replace the human factor or the regular microscope.

Modern Pathology (2010) 23, 349-358; doi:10.1038/modpathol.2009.190; published online 15 January 2010
\end{abstract}

Keywords: informatics; pathology; telepathology; digital imaging; virtual microscopy; computer

This review is directed to practicing anatomical pathologists, especially in non-academic institutions, pathology residents, and medical staff to draw their attention to the emerging and rapidly growing field of informatics in pathology practice. Our objective is to provide a simplified, yet comprehensive, overview of the diverse applications of informatics in anatomical pathology, the challenges faced

Correspondence: Dr GM Yousef, MD, PhD, FRCPC (Path), Department of Laboratory Medicine, St Michael's Hospital, 30 Bond Street, Toronto, ON, M5B 1W8, Canada.

E-mail: yousefg@smh.toronto.on.ca

Received 21 September 2009; revised 25 November 2009; accepted 7 December 2009; published online 15 January 2010 in our transition into an era of pathology informatics, and a vision of how informatics could be incorporated into our practice in the near future. We will start by defining pathology informatics. We will then summarize the spectrum of applications of informatics in pathology and the overview of the most commonly used informatics tools. We will also address some of the challenges that are faced in the transition to the era of pathology informatics and provide a glimpse into the future of pathology informatics. We will try as much as we can, to avoid technical details and sophistications regarding specific applications, referring the reader to more specialized articles and textbooks in this regard..$^{1-4}$ 


\section{What is pathology informatics?}

As is the case with other informatics applications, there is no universally accepted definition or classification for the field of pathology informatics. Many closely related terms are being used recently in the literature. In general, informatics in the medical field can be simply considered as the science that uses highly advanced technologies to apply medical or biological information to improve patient diagnosis or management. A more 'formal' definition of pathology informatics was recently proposed as 'the study of how complex sets of data are acquired, stored, processed, retrieved, analyzed, and presented, in such a way so as to turn data into information.' ${ }^{3}$ These data sets include histopathology and cytology reports, laboratory test results, image files, clinical findings, and experimental research data. Regardless of the academic argument, informatics is simply the intersection between medical data and highly advanced technologies (usually through computers) in order to use them better. Pathology informatics was created as a response to the overwhelming amount of data and information that was available, in an attempt to provide better cost-effective patient services.

\section{Tools of pathology informatics}

The most commonly used tools of informatics can be classified into digital imaging and virtual microscopy, telepathology, as well as Internet and electronic data mining. It should be noted that these tools are overlapping, and that this is an arbitrary classification created to facilitate discussion and understanding of the subject. In the next section, we discuss some of these tools and their revolutionary contribution to pathology informatics in more detail.

\section{Digital Imaging and Virtual Microscopy}

Digital imaging is the storage of anatomical pathology information, either gross pictures or microscopic slides, in an electronic format. These images can be used for education, medical literature, archival, quality control, diagnosis, and patient reports. ${ }^{5-7}$ For many years, microscopic details were stored for archival or teaching purposes in the form of glass slides. However, glass slides, have many inherent problems. Probably the most important problem with glass slides is the need for a lot of space for storage and archival. Added to this, glass slides are fragile and difficult to transport. Moreover, they cannot be stored for an unlimited period of time and will eventually fade and need to be replaced. In addition, they are not easily retrieved and shared for educational purposes. ${ }^{1,8}$ In recent years, digital imaging has emerged as a very effective alternative to the classic glass slide storage for various purposes. Digital imaging provides solutions to many of the glass slide limitations. Table 1 summarizes the major applications of digital imaging in anatomical pathology and their advantages. Moreover, digital imaging is a new flexible tool for adjusting, enhancing, and annotating medical images. Image storage is permanent and annotation can be performed over them and can also be saved. A recent study has shown the potential of digital microscopy in offering widespread utilization in breast histopathology for both diagnostics and research applications. ${ }^{9}$

Virtual microscopy (also known as virtual slides) is the more advanced form of digital imaging. It can be defined as the high-resolution digital scanning of an entire glass slide, as compared with selected views at a fixed magnification, to generate a virtual slide that can be viewed online. ${ }^{10,11}$ The introduction of virtual slides instead of digital snapshots has overcome many limitations of digital imaging. Its advantages include efficiency and accessibility of imaging. ${ }^{12}$ Improved efficiency stems from accessibility of the whole slide in an extraordinary quality at lower magnifications. With virtual microscopy, a pathologist can zoom into higher power of the area of interest. Accessibility of web-based virtual microscopy allows many pathologists to contribute to teleconsultation and education. ${ }^{13}$

Virtual microscopy is widely accepted in pathology for educational purposes and teleconsultation, but is far from the routine use in surgical pathology because of technical requirements and some limitations. Technical problems include delayed transmission rate and presentation time on the screen.

Table 1 The scope of applications of digital imaging in anatomic pathology

\begin{tabular}{|c|c|}
\hline Application & Advantages \\
\hline \multirow{3}{*}{$\begin{array}{l}\text { Archival and storage } \\
\text { of glass slides }\end{array}$} & Easy retrieval \\
\hline & Permanent (no fading) \\
\hline & Less space \\
\hline \multirow{9}{*}{$\begin{array}{l}\text { Education (medical } \\
\text { students, residents, } \\
\text { and CMA) }\end{array}$} & Easy retrieval \\
\hline & Easy to share with audience \\
\hline & Less preparation time \\
\hline & Accessibility to remote locations \\
\hline & Simultaneous availability to \\
\hline & multiple centers \\
\hline & Availability of rare cases \\
\hline & Less cost in examination preparation \\
\hline & Clarity and consistency \\
\hline \multirow{3}{*}{$\begin{array}{l}\text { Patient diagnosis } \\
\text { and management }\end{array}$} & More accurate quantification \\
\hline & (eg, ER, PR receptor status) \\
\hline & Easier for consultation \\
\hline \multirow{3}{*}{$\begin{array}{l}\text { Consultation } \\
\text { services }\end{array}$} & Easier transportation \\
\hline & Less costly \\
\hline & Faster \\
\hline \multirow[t]{3}{*}{ Gross pathology } & Permanent record of gross specimens \\
\hline & Minimize time consuming and \\
\hline & lengthy descriptions \\
\hline \multirow[t]{3}{*}{ Quality assurance ${ }^{66}$} & Consistency among centers \\
\hline & Less costly \\
\hline & Allows wider range of cases \\
\hline
\end{tabular}


Perhaps the most important challenges that need to be addressed are the cost of electronic storage, and the need to train the pathology health team and restructure the pathology department in the hospital to accommodate these new changes. These are discussed further in the next section.

A recent pilot study in Norway concluded that virtual slide technology has adequately met the diagnostic objectives, although it cannot fully replace traditional routine pathology reporting. ${ }^{10} \mathrm{~A}$ recent review addressed the many advantages and applications of digital slides and telepathology, ${ }^{6}$ including the ability to produce identical images in multiple computer screens without being damaged or causing problems of storage or retrieval, and the decrease in problems associated with mail, travel, and time. The software can also be easily manipulated for research and for routine diagnosis. It was concluded that although two main challenges exist, which are developing more user friendly software suitable for research and routine needs, and for improving image storage and capacity of hard disks, overcoming these limitations may truly revolutionize pathology across the globe.

\section{Telepathology: Applications and Limitations}

Telepathology can be defined as the remote primary diagnosis, consensus diagnosis, case conferencing, or expert consultation of either electronically transmitted, static, digitalized images, or real-time pictures obtained using remote robotic microscopes. ${ }^{14}$ In simple words, telepathology is the work of a pathologist located at a distance. ${ }^{15,16}$

It has become relatively easier to install telepathology in most pathology departments. As any pathology department will have microscopes and computers with Internet connection, with a few added elements (such as a camera connected to the microscope and software for remote image transmission), a telepathology station can be constructed. ${ }^{17}$ The Internet serves as a repository of information and transmission of images and is one of the easiest infrastructures to use in this aspect to allow global consultation. ${ }^{18}$
Different types of telepathology communications are available for diagnostic and consultation services, which were reviewed in detail in the study by Cross $^{19}$ As shown in Table 2, static image telepathology is the simple form of telepathology communication, which functions by capturing selected digital images at one site and thereafter by transmitting them electronically in the form of email attachments to the remote site. ${ }^{20}$ This method has some advantages such as low cost, but its major limitation is sampling error. ${ }^{19,21}$ The second type is dynamic robotic telepathology, which is the transmission of real-time images from robotic microscope so that distant operators have complete control over the received images. ${ }^{16,19,22}$ The major drawback of this method is its high cost, but its advantages include controlling image viewing with no sampling errors. The third type is hybrid telepathology, which involves simultaneous transmission of both realtime microscopy and static images. ${ }^{23}$

Telepathology was first used for intra-operative consultation in Norway in $1989 .{ }^{1}$ Nowadays, the application of telepathology has expanded to include primary diagnosis and a second opinion from experts. ${ }^{24}$ More recently, some institutions, such as the AFIP (Armed Forces Institute of Pathology), offer diagnostic services using telepathology. ${ }^{25}$

Although telepathology faced great resistance in the beginning, it is now increasingly becoming a useful tool in anatomical pathology practice. The scope of telepathology applications, with their limitations is summarized in Box 1. One primary application of telepathology is consultation. ${ }^{26}$ This can be either a primary (as in intra-operative frozen section consultation) $)^{27}$ or a secondary opinion. Limitations of telepathology for consultation include poor resolution of image, inappropriate field selection, lack of clarity at lower power, and poor nuclear details. These limitations are mainly related to static telepathology-based consultations, which can be largely overcome by the use of whole-slide imaging with much higher-resolution pictures. ${ }^{28}$

The diagnostic accuracy of telepathology

The diagnostic accuracy of telepathology, as compared with routine glass slides, is still a matter of

Table 2 Types of telepathology and their potential applications and disadvantages

\begin{tabular}{|c|c|c|}
\hline Туре & Applications & Disadvantages \\
\hline Simple store-and-forward telepathology & $\begin{array}{l}\text { Second opinion } \\
\text { Consultation }{ }^{67} \\
\text { Continuing education }\end{array}$ & $\begin{array}{l}\text { Acquiring images is labor intensive } \\
\text { Possibility of sampling error }\end{array}$ \\
\hline Robotic telepathology & $\begin{array}{l}\text { Frozen-section diagnosis }{ }^{68,69} \\
\text { Second opinion consultation }\end{array}$ & $\begin{array}{l}\text { Expensive } \\
\text { No interoperability between different manufacturers } \\
\text { High bandwidth requirements }\end{array}$ \\
\hline $\begin{array}{l}\text { Hybrid telepathology (interactive and } \\
\text { store-and-forward telepathology) }\end{array}$ & $\begin{array}{l}\text { Continuing education } \\
\text { Second opinion } \\
\text { Digital archiving } \\
\text { Medical education }\end{array}$ & $\begin{array}{l}\text { High initial cost } \\
\text { Scanning process can take several hours } \\
\text { Difficulty digitizing thick specimens with multiple } \\
\text { focal planes }\end{array}$ \\
\hline
\end{tabular}


Box 1 Common applications, advantages, and limitations of telepathology in anatomical pathology practice

\begin{tabular}{|l|}
\hline Applications \\
Diagnostic \\
Routine diagnosis for remote sites \\
Consultation \\
Frozen sections (diagnosis and consultation) \\
Teleconferences \\
Education \\
Advantages \\
Easier \\
Less cost \\
Faster service \\
Improved diagnostic accuracy \\
Pathology service becomes available to remote areas \\
with better allocation of pathologists manpower \\
On spot discussion with the expert \\
Limitations and challenges \\
Inappropriate field selection \\
Lack of depth perception \\
Poor nuclear details \\
Time lag between different fields \\
Poor resolution \\
Inconvenience \\
Not suitable for every case \\
Set up costs
\end{tabular}

debate. Odze et $a l^{28}$ reported that in cases of dysplasia with ulcerative colitis, the level of agreement of digital images was slightly lower than that obtained after reviewing the original glass slides. However, this study used static selective fields for consultation. In the field of cytopathology, only a limited number of studies reported diagnostic accuracy (ie, correct telecytology diagnosis correlating with the final pathology diagnosis). Earlier studies have found the accuracy of telecytology to be less than that of light microscopy. ${ }^{29}$ In conjunction with technological advances, more recent studies have shown improved accuracy. ${ }^{30}$ The studies by Leinweber et $a l^{31}$ and Morgan et $a l^{32}$ have shown that telepathology is a suitable solution in diagnosing melanocytic lesions with a great diagnostic accuracy. These studies and others have shown that telepathology represents a valuable method for quality assurance in dermatopathology. ${ }^{31-34}$

Recently, Evans et $a l^{35}$ conducted a study that analyzed 983 frozen section diagnoses collected from 790 patients, which were made by robotic microscopy telepathology. In this analysis, the diagnostic accuracy was $98 \%$, whereas the overall deferral rate was only $7.7 \%$, and the mid-case technical failure rate was only $0.3 \%$. It was observed that discrepant cases usually involved minor interpretative errors related to tumor type, none of which had any clinical impact to date.

More recently, Lopez et al ${ }^{36}$ described a telemedicine-enabled service, which combined telemammography, telepathology, and teleoncology in a single-day process. Although the core services were positioned at four different physical locations, virtual slide telepathology was used to provide immediate quality assurance re-review of diagnosed breast cancer cases. Complete concurrence occurred with primary diagnoses in $90.3 \%$ of cases. Only $4.3 \%$ of the cases resulted in major discrepancies, $1.9 \%$ had minor discrepancies, $1.9 \%$ were deferred for immunohistochemistry, and $1.3 \%$ of the cases were deferred for examination of glass slides. In a study by Kerr et $a l,{ }^{37}$ a telepathology system for consultation between residents and faculty for the assessment of specimen adequacy and preliminary diagnosis was evaluated. A total of 100 consecutive cases were used to compare findings with the original assessment of adequacy, interpretation, and diagnosis, resulting in $97 \%$ diagnostic concordance and 99\% accuracy. Another study conducted by Eichhorn et $a l^{38}$ performed a retrospective analysis of 191 gynecological cytology slides. Data were reviewed by three cytotechnologists and three cytopathologists. In $89 \%$ of cases, $\geq 3$ reviewers agreed on correct characterization. However, $83 \%$ of the cases were categorized as 'abnormal' (neither unsatisfactory nor negative for intra-epithelial lesion or malignancy).

Other applications of telepathology are surgical specimen manipulation, ${ }^{39}$ fine needle aspiration cytology evaluation, ${ }^{40}$ cytology screening, ${ }^{4,30}$ autopsy assistance, ${ }^{39}$ and molecular pathology guidance. $^{39}$ One interesting application of telepathology is Internet-based teleconferencing. This technology allows the referring pathologist to transmit real-time images from a microscope to a consultant, while maintaining a verbal conversation using Internet telephony. ${ }^{41}$ Internet-based teleconferencing techniques provide effective and relatively inexpensive tools for real-time telepathology consultations. The technology is probably best suited for the study of small specimens obtained from patients who require rapid diagnosis by a consultant.

The terms 'virtual microscopy' and 'telepathology' are often confusing. Dynamic telepathology refers to remote robotic operation of a motorized microscope and real-time transmission of a video image. ${ }^{3}$ In contrast, virtual microscopy is a form of static telepathology, in which digital imaging technology is used to digitize, store, and view slides. ${ }^{42} \mathrm{~A}$ digital representation of an entire slide at the resolution of a high-magnification objective is designated a 'virtual slide.' The application spectrum of dynamic telepathology is limited by its 'live' nature and single user control, whereas virtual slides archived on a network server can be individually controlled and simultaneously viewed by a large number of users. ${ }^{43}$ This is the key to a wide range of potential applications of virtual microscopy, from production of educational material to integration into the hospital patient record system. ${ }^{4}$ 


\section{Internet and Electronic Data Mining}

Data mining can be defined as deriving information from existing data sources in the Internet. ${ }^{45}$ The age of pathology informatics has provided a spectrum of help for practicing anatomical pathologists. Table 3 summarizes some of the useful pathology Internet resources, which provide great support to pathologists. Pathologists are now able to perform a quick search for visual representation of rare cases and search for quick updates in a certain field or diagnostic category. They can quickly search the web for differential diagnosis of a specific morphology or look up the diagnostic criteria for a certain disease entity. Moreover, diagnosis-related web sites can help the anatomical pathologist to order the appropriate immunohistochemistry panel, or to review the molecular abnormalities associated with various diseases. ${ }^{46,47}$ Information on the web has become increasingly useful to pathologists and has provided a new opportunity for training, sharing research publications, and continuing medical education. ${ }^{45,48}$ The Internet has also provided a mechanism for web-based training in remote and underserved areas to gain updates on new entities and classification systems. ${ }^{49}$

In addition, many journals are now becoming freely accessible in an electronic format, saving a lot of time, effort, and resources. More recently, we are moving into an era of 'open-access' journals that are completely freely available to the reader. These journals are usually funded by authors of the articles. Moreover, almost all pathology textbooks now offer an electronic version that is easily searchable. There are some pitfalls of using the Internet for mining data. One of the critical drawbacks is the questionable accuracy of the information offered.

Table 3 Useful Internet resources for practicing pathologists

\begin{tabular}{|c|c|c|}
\hline Application & Web site & Web address \\
\hline $\begin{array}{l}\text { Immunohistochemistry } \\
\text { selection }\end{array}$ & PathIQ ImmunoQuery & https://immunoquery.pathiq.com/PathIQ/Login.do \\
\hline \multirow[t]{5}{*}{ Surgical pathology } & $\begin{array}{l}\text { Department of Pathology, University } \\
\text { of Pittsburgh }\end{array}$ & http://path.upmc.edu \\
\hline & Pathmax & www.pathmax.com/main.html \\
\hline & PathCONSULT & www.pathconsultddx.com \\
\hline & PathologyOutlines & www.pathologyoutlines.com/ \\
\hline & USCAP e Academy & www.uscapeacademy.org/index.htm?home.htm \\
\hline \multirow[t]{2}{*}{ Genitourinary pathology } & $\begin{array}{l}\text { WHO/ISUP urothelial neoplasms } \\
\text { classification }\end{array}$ & http://162.129.103.34/bladder/ \\
\hline & Gleason’s grading of prostate cancer & http://162.129.103.34/prostate/ \\
\hline \multirow{3}{*}{$\begin{array}{l}\text { Ob-Gyn pathology } \\
\text { Case reports, literature } \\
\text { search, and educational } \\
\text { material }\end{array}$} & Tumors of female reproductive organs & http://www.bioscience.org/atlases/tumpath/freprod \\
\hline & PubMed & http://www.ncbi.nlm.nih.gov/PubMed/ \\
\hline & $\begin{array}{l}\text { USCAP educational material } \\
\text { Medscape } \\
\text { University of Western Ontario Pathology } \\
\text { Resources }\end{array}$ & $\begin{array}{l}\text { http://www.uscap.org/ } \\
\text { http://www.medscape.com/ } \\
\text { http://www.uwo.ca/pathol/resources.html }\end{array}$ \\
\hline Oncopathology & $\begin{array}{l}\text { College of American Pathologists (CAP) } \\
\text { Cancer Protocols and Checklists }\end{array}$ & http://www.cap.org/ \\
\hline Transplant pathology & University of Pittsburgh & http://tpis.upmc.com/TPIShome/ \\
\hline Pulmonary pathology & Pneumo Tox & http://www.pneumotox.com/ \\
\hline Frozen sections & $\begin{array}{l}\text { Frozen consult: methods, indications, and } \\
\text { reports }\end{array}$ & http://www.pathologie-fuerth.de/methods.html \\
\hline Hematopathology & Lymphoma network & http://www.lymphomainfo.net/nhl/classify \\
\hline Cytopathology & CYTOPATHNET & http://cytopathnet.org/ \\
\hline \multirow[t]{2}{*}{ Forensic pathology } & $\begin{array}{l}\text { The Wellcome trust: Forensic medicine for } \\
\text { medical students }\end{array}$ & http://www.forensicmed.co.uk/ \\
\hline & John Hopkins autopsy resource & http://www.autopsydb.org/ \\
\hline Dermatopathology & Dermpath tutor & http://tray.dermatology.uiowa.edu/DPT/Path-index.htm \\
\hline \multirow[t]{3}{*}{ Pathology informatics } & $\begin{array}{l}\text { Advancing Practice, Instruction and } \\
\text { Innovation through Informatics (APIII) }\end{array}$ & http://apiii.upmc.edu \\
\hline & Lab Infotec Summit & http://www.labinfotech.com \\
\hline & Association for Pathology Informatics & http://www.pathologyinformatics.org \\
\hline \multirow[t]{6}{*}{ Pathology blogs } & Neuropathology blog & $\begin{array}{l}\text { http://neuropathologyblog.blogspot.com/2009/08/ } \\
\text { pittsburgh-pathology-informatics-summit.html }\end{array}$ \\
\hline & Digital pathology blog & http://www.tissuepathology.typepad.com/weblog/ \\
\hline & Dark Daily & http://www.darkdaily.com/ \\
\hline & Lab Soft News & http://labsoftnews.typepad.com/ \\
\hline & Pathology Informatics from the Trenches & http://pathologyinformaticstrenches.blogspot.com/ \\
\hline & The Daily Sign-Out & $\begin{array}{l}\text { http://pathlabmed.typepad.com/ } \\
\text { surgical_pathology_and_la/ }\end{array}$ \\
\hline
\end{tabular}


Recently, a number of pathology informatics web sites are available, which provide a wealth of informatics-related resources for a practicing pathologist. Moreover, several pathology blogs are available. A partial list of some of these resources is shown in Table 3.

\section{The scope of pathology informatics}

The spectrum of applications of informatics in the field of anatomical pathology is broad and not yet clearly defined. As shown in Table 4 and Figure 1, applications can be roughly divided into three major categories to facilitate our understanding. These are medical education, clinical services, and pathology research. However, we should realize that many of these applications are overlapping.

As discussed above, informatics is now settling on solid ground as an important tool for pathology education, with digital teaching tools and archrivals becoming standard tools in many universities and teaching hospitals. ${ }^{50}$ An interesting rapidly growing field is the integration of informatics tools for automated clinical decision support, from anatomical pathology case diagnosis and consultation to patient management, risk assessment, and quality assurance, in addition to others. ${ }^{51}$

In the next section, we discuss the impact of informatics on clinical patient management and on translational research in pathology in more detail.

Table 4 The Spectrum of applications of informatics in the Field of anatomical pathology

\begin{tabular}{ll}
\hline Application & Examples \\
\hline Education & Teaching: \\
& Medical students \\
& Pathology residents and fellows \\
& Laboratory technologists \\
& Pathology assistants \\
& Research graduate students \\
& Conferences presentations \\
& Scientific publications \\
& Self-study and CME \\
& Digital storage of teaching collections of gross \\
& and microscopic images of cases \\
& Case diagnosis and consultation \\
& Immunohistochemistry panel selection \\
& Frozen section diagnosis and consultation \\
Clinical & Development of prognostic models \\
& Development of multidisciplinary \\
& treatment algorithms \\
& Quality assurance \\
& Data retrieval/electronic medical records \\
& Autopsy reporting \\
& Digital archrivals of gross and microscopic \\
images of patient cases \\
Development of new prognostic and predictive \\
molecular markers \\
Analysis of molecular profiling data \\
Pathway analysis \\
Protein-protein interaction analysis \\
Integration of data from multiple sources \\
& \\
& \\
& \\
&
\end{tabular}

The Impact of Pathology Informatics on Patient Management (Moving Toward Real-Life Applications)

Perhaps one of the most important evolving fields is the ability of informatics to provide computerassisted, statistically accurate decision support for patient diagnosis, prognosis, and management. ${ }^{3,52}$ After several years of slow start, we have witnessed the transition of informatics from the research bench to bedside. A number of commercial vendors now provide computer-assisted accurate statistically base decision for prognostic and predictive markers. A common example is the automated assessment of immunohistochemistry for the ER, PR, and Her-2neu in breast cancer that has proven to be a more accurate, reproducible, and time-saving method compared with manual evaluation.

A number of commercial panel-based tests are now available for tumor diagnosis and classification. Exciting new examples are slowly emerging. A few include miRview microRNAs-based testing to differentiate between lung adenocarcinoma and mesothelioma, and mRNA-based tests to identify the tissue of origin of primary unknown cancer. ${ }^{53,54}$ Molecular-based testing for prognostic purposes that incorporates information from multiple parameters are already available, eg, the mRNA-based OncoType test..$^{55}$

It should also be noted that pathology informatics is not moving forward in isolation, but is rather integrated in the consortium of informatics revolution that involves various applications related to patient management. The health system is moving forward into an era of electronic data storage and management, and toward integrating and linking data obtained from different sources. As a natural extension of informatics age, electronic medical records are now increasingly replacing paper archives for pathology reporting, as is with other medical specialties. ${ }^{3}$ The replacement of ordinary dictation of pathology reports by the voice recognition system is also emerging now with improving success.

\section{Informatics in Pathology Translational Research}

An important application of informatics in pathology that is usually overseen by practicing pathologists is the field of translational research. From a research perspective, pathology informatics involves the management and analysis of complex sets of data obtained from various experiments. ${ }^{56}$ At present, an increasing number of large-scale experiments have been conducted at multiple levels including mRNA expression analysis, proteomics, and tissue microarrays. These experiments generated an enormous amount of data that could not be interpreted manually and necessitated the use of high-tech computer software to facilitate the integration and correlation of data from different sources for achieving more understanding of disease 


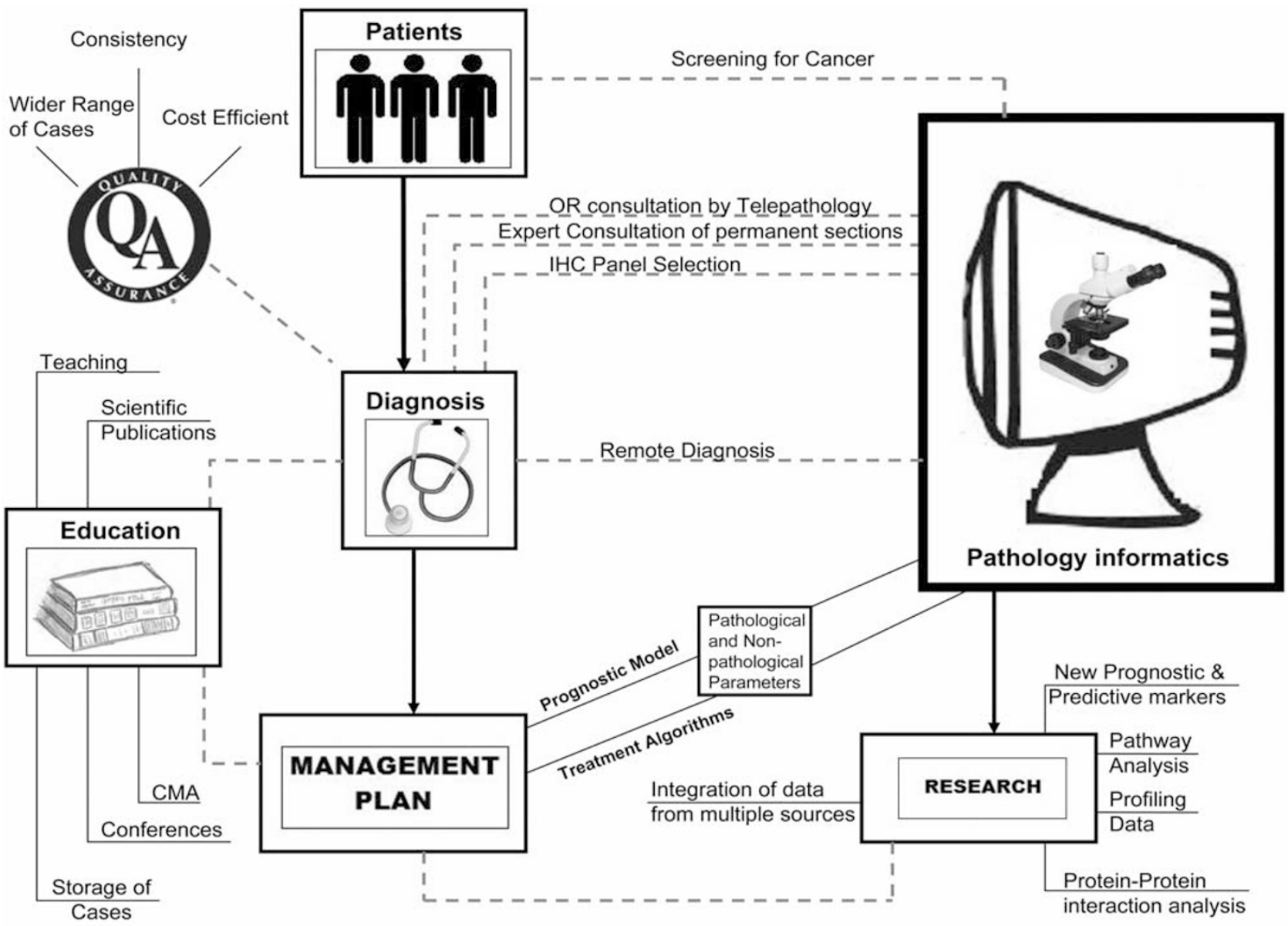

Figure 1 A schematic showing the possible scenarios of the incorporation of informatics into the field of anatomical pathology.

pathogenesis, with the final goal of improving patient diagnosis and management. Informatics offer a great advantage of interpreting data from multiple dimensions to shape one comprehensive picture that informs us about the evolution and pathogenesis of different diseases.

A key step to improve translational research is the development of tissue banking and electric repository of clinicopathological databases of diseases. Several initiatives have been implemented in major institutions. ${ }^{56}$ In this regard, synoptic reporting provides a structured method for storing diagnostic and prognostic information for each patient to allow further analysis and interpretation of data. Another strategic movement in the right direction is the availability of global repositories and databases for particular diseases, such as microarray expression profiles of mRNA, proteins, and miRNAs.

Entering into the era of pathology informatics, our research focus started to switch from a 'singlemolecule' approach to a more global picture that analyzes several hundred thousands of molecules at the same time. This not only speeds biomarker and treatment discoveries but also allows a new dimension of research that is the understanding of the cross-talk between molecules (eg, in the form of pathways that lead to the development of disease, etc). ${ }^{57}$

\section{Challenges for pathology informatics}

As we are moving into a new era of extensive pathology informatics utilization, several challenges have to be addressed. One of the most important challenges is the cost of the new technology. Initial transfer into a digitalized system will require significant spending for building the new system. To date, a limited number of institutions are adopting digital pathology because of the high cost and complexity of equipments. Prices are, however, becoming much more affordable than they were a few years ago as the technology became more widespread. After initial capital investment, additional running costs are becoming minimal. Moreover, the Internet simplified communications and overcame the problem of installing specialized lines to communication equipment. ${ }^{58}$ The increasing cost of this high-tech informatics system is balanced on the other hand by reducing the cost of storage $^{59}$ and eliminating many of the expenses associated with glass slides. 
Recently, studies have introduced the option of 'portable telepathology,' which can be very useful, cost effective, and easy to implement. All that is required to implement this system is a camera, a universal microscope adapter for the camera, a device to connect the camera to the computer, and software for the remote image transfer. ${ }^{17,60}$

Another important challenge that is usually overseen is the attitude of practicing pathologists toward this change. Generally speaking, a good percentage of anatomical pathologists are not in favor of the transition into digital practice. This can be attributed to many factors, including the less clear understanding of the nature and details of digital pathology, including its limitations. Some pathology cases (eg, the thick smear of cytology specimens) ${ }^{30,61}$ cannot be simply diagnosed by telepathology. ${ }^{3}$ Moreover, there is generally a lesser level of comfort with the new procedures as is the case with any new practice. Another important factor that causes resistance among pathologists is the feeling that pathologists will have less control over this new mechanism. ${ }^{3}$

Another practical reason why pathologists are resistant to telepathology is the fear of missing critical diagnostic regions. ${ }^{62}$ This has been largely overcome by whole-slide scanning in virtual microscopy. ${ }^{19}$ Moreover, the image files of virtual microscopy are large and thus their transmission might be problematic. Another problem we need to face is the image production turn-around time especially with large-size files. Initially, scanning a whole slide was a very lengthy procedure. ${ }^{1,8}$ Scanning time and efficiency are now becoming much faster and better, respectively. A recent study showed that using image compression can reduce image files to approximately one-tenth their original size. Such a compression may be beneficial in reducing transmission time over the Internet. ${ }^{63}$ Using high bandwidth communications for faster transmission of images is very helpful, especially in dynamic telepathology. ${ }^{19}$ Advances in wireless telecommunications will also enhance telepathology applications from the point of view of transmission of images and convenient access to the Internet web servers. ${ }^{64}$

It has been recently suggested that failure to adopt a digital imaging technology may eventually become a handicap and can be viewed in the future as a deficiency of practice. ${ }^{8}$

After witnessing other successful examples in other medical disciplines (such as radiology), we can be more comfortable in drawing the conclusion that pathology will be no exception. It should be considered that not every anatomical pathologist is good with using computers and their applications. Thus, training the pathologists is essential to achieve more understanding of the nature and limitations of these transitions in addition to new benefits for our future practice.

Legal issues related to archiving and protection of electronic data should be also seriously considered.
The use of the Internet for store-and-forward telepathology introduces new problems, mainly related to the quality of service from the security and performance points of view; such problems could be partially eliminated using Intranets, ie, private networks in which Internet protocols are adopted. However, privacy issues of telemedicine are almost the same as electronic commerce; thus, solutions currently studied and adopted for it could represent the manner by which secure communications can be carried out for telemedicine applications. ${ }^{65}$ Patient confidentiality should be ensured when we start using telepathology, and data protection is highly essential.

\section{Pathology informatics: a glimpse into the future}

It is clear from current evidence that pathology informatics will continue to grow and have a major role in the future of anatomical pathology. However, it is also clear that certain informatics applications, such as telepathology, are not going to fully replace the human factor or the regular microscope. In other words, it is unlikely that in a few years pathologists will no longer have microscopes at their workstation but rather just a computer monitor. ${ }^{3}$ After the period of initial enthusiasm, we arrived at a more practical perspective regarding the involvement of various informatics applications in the future of pathology. Figure 1 shows a scheme of how informatics will be integrated into the anatomical pathology practice.

The era of pathology informatics is likely to revolutionize the duties of the pathologist from a data interpreter or a simple diagnosis provider to more active involvement in patient management, including prognosis assessment and choosing the best-individualized treatment options. Information from histological parameters will be augmented by immunohistochemical and molecular testing results and clinical data. Informatics will guide the incorporation of new molecular and tissue-based testing that can be used to modify our current (anatomicalbased) tissue diagnosis into a more accurate and detailed classification of diseases. A good example of this is the recent leukemia and lymphoma classification that incorporates other testing results in addition to the $\mathrm{H} \& \mathrm{E}$ tissue diagnosis.

In an optimistic view, the era of informatics will turn the pathologist into a 'diagnostic specialist' who will be able to integrate data obtained from different sources $^{3}$ to a disease-based integrative report that is more clinically useful than any of its elements by themselves. ${ }^{3}$

\section{Disclosure/conflict of interest}

The authors declare no conflict of interest. 


\section{References}

1 Leong FJ, Leong AS. Digital imaging applications in anatomic pathology. Adv Anat Pathol 2003;10:88-95.

2 Glatz-Krieger K, Spornitz U, Spatz A, et al. Factors to keep in mind when introducing virtual microscopy. Virchows Arch 2006;448:248-255.

3 Sinard JH. Practical Pathology Informatics: Demystifying Informatics for Practicing Anatomic Pathologist, 1st edn. Springer: New York, 2009.

4 Alli PM, Ollayos CW, Thompson LD, et al. Telecytology: intraobserver and interobserver reproducibility in the diagnosis of cervical-vaginal smears. Hum Pathol 2001;32:1318-1322.

5 Pritt BS, Gibson PC, Cooper K. Digital imaging guidelines for pathology: a proposal for general and academic use. Adv Anat Pathol 2003;10:96-100.

6 Rocha R, Vassallo J, Soares F, et al. Digital slides: present status of a tool for consultation, teaching, and quality control in pathology. Pathol Res Pract 2009; 205:735-741.

7 Weinstein RS. Innovations in medical imaging and virtual microscopy. Hum Pathol 2005;36:317-319.

8 Leong FJ, Leong AS. Digital imaging in pathology: theoretical and practical considerations, and applications. Pathology 2004;36:234-241.

9 Krenacs T, Zsakovics I, Diczhazi C, et al. The potential of digital microscopy in breast pathology. Pathol Oncol Res 2009;15:55-58.

10 Slodkowska J, Chyczewski L, Wojciechowski M. Virtual slides: application in pulmonary pathology consultations. Folia Histochem Cytobiol 2008;46:121-124.

11 Isabelle M, Teodorovic I, Oosterhuis JW, et al. Virtual microscopy in virtual tumor banking. Adv Exp Med Biol 2006;587:75-86.

12 Sato T, Miura T, Nozaka H, et al. [Progression in diagnostic pathology; development of virtual microscopy and its applications]. Rinsho Byori 2007;55:344-350.

13 Lee SH. Virtual microscopy: applications to hematology. Lab Hematol 2005;11:38-45.

14 Weinstein RS, Bhattacharyya AK, Graham AR, et al. Telepathology: a ten-year progress report. Hum Pathol 1997;28:1-7.

15 Kayser K, Kayser G, Radziszowski D, et al. From telepathology to virtual pathology institution: the new world of digital pathology. Rom J Morphol Embryol 1999;45:3-9.

16 Kayser K, Beyer M, Blum S, et al. Recent developments and present status of telepathology. Anal Cell Pathol 2000;21:101-106.

17 Alfaro L, Roca MJ. Portable telepathology: methods and tools. Diagn Pathol 2008;3(Suppl 1):S19.

18 Leong FJ. Practical applications of Internet resources for cost-effective telepathology practice. Pathology 2001;33:498-503.

19 Cross SS, Dennis T, Start RD. Telepathology: current status and future prospects in diagnostic histopathology. Histopathology, 2002 Aug; 41:91-109. PubMed PMID: 12147086.

20 Weinstein RS. Static image telepathology in perspective. Hum Pathol 1996;27:99-101.

21 Gombas P, Skepper JN, Hegyi L. The image pyramid system-an unbiased, inexpensive and broadly accessible method of telepathology. Pathol Oncol Res 2002;8:68-73.

22 Wells CA, Sowter C. Telepathology: a diagnostic tool for the millennium? J Pathol 2000;191:1-7.
23 Zhou J, Hogarth MA, Walters RF, et al. Hybrid system for telepathology. Hum Pathol 2000;31:829-833.

24 Fronza CF, Fronza H Jr. Telepathology: diagnostic aid, second medical opinion and validation of the diagnostic efficiency. AMIA Annu Symp Proc, 2007 Oct 11: 958. PubMed PMID: 18694058.

25 Williams BH, Mullick FG, Butler DR, et al. Clinical evaluation of an international static image-based telepathology service. Hum Pathol 2001;32:1309-1317.

26 Brauchli K, Oberli H, Hurwitz N, et al. Diagnostic telepathology: long-term experience of a single institution. Virchows Arch 2004;444:403-409.

27 Tsuchihashi Y, Takamatsu T, Hashimoto Y, et al. Use of virtual slide system for quick frozen intra-operative telepathology diagnosis in Kyoto, Japan. Diagn Pathol 2008;3(Suppl 1):S6.

28 Odze RD, Goldblum J, Noffsinger A, et al. Interobserver variability in the diagnosis of ulcerative colitis-associated dysplasia by telepathology. Mod Pathol 2002;15:379-386.

29 Raab SS, Zaleski MS, Thomas PA, et al. Telecytology: diagnostic accuracy in cervical-vaginal smears. Am J Clin Pathol 1996;105:599-603.

30 Steinberg DM, Ali SZ. Application of virtual microscopy in clinical cytopathology. Diagn Cytopathol 2001;25:389-396.

31 Leinweber B, Massone C, Kodama K, et al. Teledermatopathology: a controlled study about diagnostic validity and technical requirements for digital transmission. Am J Dermatopathol 2006;28:413-416.

32 Morgan MB, Tannenbaum M, Smoller BR. Telepathology in the diagnosis of routine dermatopathologic entities. Arch Dermatol 2003;139:637-640.

33 Piccolo D, Soyer HP, Burgdorf W, et al. Concordance between telepathologic diagnosis and conventional histopathologic diagnosis: a multiobserver store-andforward study on 20 skin specimens. Arch Dermatol 2002;138:53-58.

34 Shapiro M, James WD, Kessler R, et al. Comparison of skin biopsy triage decisions in 49 patients with pigmented lesions and skin neoplasms: store-andforward teledermatology vs face-to-face dermatology. Arch Dermatol 2004;140:525-528.

35 Evans AJ, Chetty R, Clarke BA, et al. Primary frozen section diagnosis by robotic microscopy and virtual slide telepathology: the University Health Network experience. Hum Pathol 2009;40:1070-1081.

36 Lopez AM, Graham AR, Barker GP, et al. Virtual slide telepathology enables an innovative telehealth rapid breast care clinic. Hum Pathol 2009;40:1082-1091.

37 Kerr SE, Bellizzi AM, Stelow EB, et al. Initial assessment of fine-needle aspiration specimens by telepathology: validation for use in pathology resident-faculty consultations. Am J Clin Pathol 2008;130:409-413.

38 Eichhorn JH, Buckner L, Buckner SB, et al. Internetbased gynecologic telecytology with remote automated image selection: results of a first-phase developmental trial. Am J Clin Pathol 2008;129:686-696.

39 Rojo MG. EURO-TELEPATH 'Telepathology Network in Europe': COST Action IC0604. http://www conganat org/eurotelepath/ 2009.

40 Della Mea V, Puglisi F, Bonzanini M. et al. Fine-needle aspiration cytology of the breast: a preliminary report on telepathology through Internet multimedia electronic mail. Mod Pathol 1997;10:636-641.

41 Marchevsky AM, Lau SK, Khanafshar E, et al. Internet teleconferencing method for telepathology 
consultations from lung and heart transplant patients. Hum Pathol 2002;33:410-414.

42 Furness PN. The use of digital images in pathology. J Pathol 1997;183:253-263.

43 Glatz-Krieger K, Glatz D, Mihatsch MJ. [Virtual microscopy: first applications]. Pathologe 2006;27:469-476.

44 Lundin M, Lundin J, Isola J. Virtual microscopy. J Clin Pathol 2004;57:1250-1251.

45 DiGiorgio CJ, Richert CA, Klatt E, et al. E-mail, the Internet, and information access technology in pathology. Semin Diagn Pathol 1994;11:294-304.

46 Talmon G, Abrahams NA. The Internet for pathologists: a simple schema for evaluating pathology-related web sites and a catalog of sites useful for practicing pathologists. Arch Pathol Lab Med 2005;129:742-746.

47 London JW, Gomella LG. Overview of the Internet and prostate cancer resources. Semin Urol Oncol 2000;18: 245-253.

48 Schenck U. Web based training in cytology [abstract]. Acta Cytol 2007;51:260-261.

49 Yuan Q, Chang AR, Ng HK. Introduction of the Bethesda System to Mainland China with a web-based tutorial. Acta Cytol 2003;47:415-420.

50 Graham AR, Bhattacharyya AK, Scott KM, et al. Virtual slide telepathology for an academic teaching hospital surgical pathology quality assurance program. Hum Pathol 2009;40:1129-1136.

51 Bates DW, Pappius E, Kuperman GJ, et al. Using information systems to measure and improve quality. Int J Med Inform 1999;53:115-124.

52 Becich MJ, Gilbertson JR, Gupta D, et al. Pathology and patient safety: the critical role of pathology informatics in error reduction and quality initiatives. Clin Lab Med 2004;24:913-943.

53 CupPrint. GeneProfiling Limted 2008. Available from: URL:http://www.geneprofilingltd.com/CupPrint.aspx.

54 Rosetta Genomics Announces Availability of Third MicroRNA-Based Diagnostic Test: miRview(TM) meso. 12-29-2008. Ref Type: Magazine Article.

55 Oncotype DX Test. Breastcancer org 2008 September 23 Available from:http://www.breastcancer.org/symptoms/ testing/types/oncotype_dx.jsp.

56 Mohanty SK, Parwani AV, Crowley RS, et al. The importance of pathology informatics in translational research. Adv Anat Pathol 2007;14:320-322.
57 Arsanious A, Bjarnason GA, Yousef GM. From bench to bedside: current and future applications of molecular profiling in renal cell carcinoma. Mol Cancer 2009;8:20.

58 Molinie V, Epardeau B, Bernier M, et al. [Low cost telepathology]. Ann Pathol 2001;21:361-366.

59 Enlander D. Computer data processing of medical diagnoses in pathology. Am J Clin Pathol 1975;63: 538-544.

60 Rainer R, Chimiak WJ, Geisinger K, et al. A flexible telepathology system, imac, pp. 0264, 4th International Conference on Image Management and Communication (IMAC 95), 1995.

61 Lee ES, Kim IS, Choi JS, et al. Accuracy and reproducibility of telecytology diagnosis of cervical smears. A tool for quality assurance programs. Am J Clin Pathol 2003;119:356-360.

62 Jimbo M, Meyer B, Hyslop T, et al. Effectiveness of complete diagnostic examination in clinical practice settings. Cancer Detect Prev 2006;30:545-551.

63 Marcelo A, Fontelo P, Farolan M, et al. Effect of image compression on telepathology. A randomized clinical trial. Arch Pathol Lab Med 2000;124: 1653-1656.

64 Frierson Jr HF, Galgano MT. Frozen-section diagnosis by wireless telepathology and ultra portable computer: use in pathology resident/faculty consultation. Hum Pathol 2007;38:1330-1334.

65 Della MV. Store-and-forward telepathology. In: European Telemedicine. PhD Institute of Pathology, University of Udine: Italy, 1998.

66 Yagi Y, Gilbertson JR. Digital imaging in pathology: the case for standardization. J Telemed Telecare 2005;11:109-116.

67 Ayad E, Sicurello F. Telepathology in emerging countries pilot project between Italy and Egypt. Diagn Pathol 2008;3(Suppl 1):S2.

68 Chorneyko K, Giesler R, Sabatino D, et al. Telepathology for routine light microscopic and frozen section diagnosis. Am J Clin Pathol 2002;117:783-790.

69 Kaplan KJ, Burgess JR, Sandberg GD, et al. Use of robotic telepathology for frozen-section diagnosis: a retrospective trial of a telepathology system for intraoperative consultation. Mod Pathol 2002;15: 1197-1204. 